Pain Physician. 2006;9:53-56, ISSN 1533-3159

A Prospective Observational Report

\title{
LUMBOSACRAL TRANSITIONAL VERTEBRAE: Incidence in a Consecutive Patient Series
}

Elva G. Delport, MD, Tony R. Cucuzzella, MD, Nancy Kim, MD, Julie Marley, PT, Dip MDT, Christine Pruitt, RN, MS, and Anton G. Delport, PT, Dip MDT

\footnotetext{
Background: Great variability exists in the reported frequency of transitional vertebra in the general population as well as in symptomatic lumbar spine patients

Objective: To determine the occurrence rate of transitional vertebra in consecutive lumbar spine patients in our practice al study

Design: A prospective, observation-

Methods: Plain films were viewed and

A transitional lumbosacral vertebra is a common congenital anomaly first observed by Bertolotti in 1917 (1). A transitional vertebra may have varying formations, the common feature being an atypical lumbosacral articulation between the transverse process(es) of the most inferior lumbar vertebrae and the sacrum. It is commonly classified based on the type of articulation between the transverse processes and the sacrum. According to Castellvi's system (2), Type I is defined as a large transverse process measuring at least $19 \mathrm{~mm}$ in width, Type II is an actual diarthrodial joint between the last transverse process and the sacrum, and Type III is a bony union between the last transverse process and the sacrum. This may occur unilaterally or bilaterally.

The clinical significance of a transitional vertebra has been frequently de-

From: Christiana Spine Center, Newark, Delaware, and Drexel University, Philadelphia, Pennsylvania

Address correspondence:

Julie Marley, PT

4735 Ogletown-Stanton Rd., Ste. 2210

Newark, DE 19713

E-mail: jkmarley@comcast.net

Disclaimer: There was no external funding in the preparation of this manuscript.

Conflict of Interest: None

Manuscript received on 5/15/2005

Revision submitted on 9/1/2005

Accepted for publication on 9/03/2005
}

the presence or absence of a lumbar transitional vertebra was documented. Transitional vertebrae were classified as incomplete or complete.

Results: Of the 300 consecutive patients, 30\% had a transitional vertebra.

Conclusion: Our percentage of $\mathrm{pa}$ tients with a transitional vertebra was higher than the percentages reported for the general population. This supports our be- lief that the alteration in mechanics caused by a transitional vertebra may at times contribute to pain generation. Additionally, as a transitional segment may not always be visualized on MRI, obtaining plain films prior to an injection or surgery will help prevent confusion over the appropriate level for the procedure.

Key words: Lumbosacral vertebra, transitional vertebra, radiology, low back pain bated. Estimates in the general population vary greatly, ranging from $4 \%-24 \%$ (3-8) depending on the sample size and the population studied. Some authors $(3,9,10)$, as well as one systematic review (11), have concluded that the incidence of transitional vertebra is equal in those with and without back pain, rendering it only an incidental finding on imaging. Other authors report higher incidences in back pain populations, ranging from $16 \%$ to $30 \%(2,4,7,12)$, as well as higher incidences of disc degeneration above the transitional segment $(2,5)$ and herniations occurring at younger ages (5).

In our practice epidural spinal injections are often performed to treat radicular pain, and selective nerve root blocks are performed as the result of requests by spine surgeons to determine the anatomic level of the pain generator prior to planning for spine surgery. The presence of a transitional vertebra can create confusion as to what level corresponds to which exiting nerve root either at the time of the injection, or the surgery. There are reports in the literature of surgery being performed at the wrong lumbar level (13) and the presence of a transitional vertebra may contribute to this error. For these reasons we feel that the presence of a transitional vertebra has clinical significance.

The purpose of this study was to as- sess the percentage of patients with a transitional vertebra in our population of low back pain patients and to compare our findings to the existing information about the incidence in the general population. Prior to initiating the study, we had noted it as a quite frequent anomalous finding in our symptomatic lumbar spine population. As previous studies provided such a wide range of incidence, we desired to determine the percentage in our own population. We thought drawing attention to the high frequency would be useful to interventional spine physicians and would help prevent confusion over nomenclature of levels, and would also lend support to our belief that the alternation in mechanics caused by a transitional vertebra may at times contribute to pain generation.

\section{Methods}

Three physicians at an outpatient spinal injection practice reviewed the plain films of 300 consecutive lumbar spine patients presenting for evaluation for axial, referred, and/or radicular pain. The research was approved by the Institutional Review Board at the local hospital. For each $\mathrm{X}$-ray viewed, the physician documented the presence or absence of a lumbar transitional vertebra. We used a classification system similar to Castellvi's, but utilized 
Table 1. Classification of transitional vertebrae

\begin{tabular}{|l|l|l|}
\hline $\begin{array}{l}\text { Incomplete } \\
\text { Unilateral } \\
\text { or bilateral }\end{array}$ & $\begin{array}{l}\text { Castellvi Type I } \\
\text { and II }\end{array}$ & $\begin{array}{l}\text { Dysplastic transverse process that articulates with the } \\
\text { sacrum or forms a diarthrodial joint with the sacrum }\end{array}$ \\
\hline $\begin{array}{l}\text { Complete } \\
\text { Unilateral } \\
\text { or bilateral }\end{array}$ & $\begin{array}{l}\text { Castellvi Type } \\
\text { III and IV }\end{array}$ & $\begin{array}{l}\text { Bony union between one or both of the transverse } \\
\text { processes with the sacrum }\end{array}$ \\
\hline
\end{tabular}

fewer groups, calling them incomplete or complete (Table 1). All types could occur unilaterally or bilaterally. The incomplete group included those films in which the most inferior lumbar vertebra had a distinct transverse process (or transverse processes) large enough that no space was visible between the transverse process(es) and the sacrum. At times this was difficult to determine accurately due to the two-dimensional nature of plain films. In these cases, if T12 had no ribs or short ribs and L4 had the normal shape of L5, the most inferior lumbar vertebra was counted as transitional.

Also included in the incomplete group were those transitional vertebra in which the transverse processes formed a diarthrodial joint with the sacrum. The complete transitional vertebra were considered those vertebrae with a clear bony union between the transverse process(es) and the sacrum

\section{RESULTS}

Of 300 consecutive lumbar spine patients, $30 \%$ had a transitional vertebra. The most frequent type was a complete bilateral $(29 \%)$. Seven percent of those that had a transitional vertebra had missing data with regard to the type (Fig. 1).

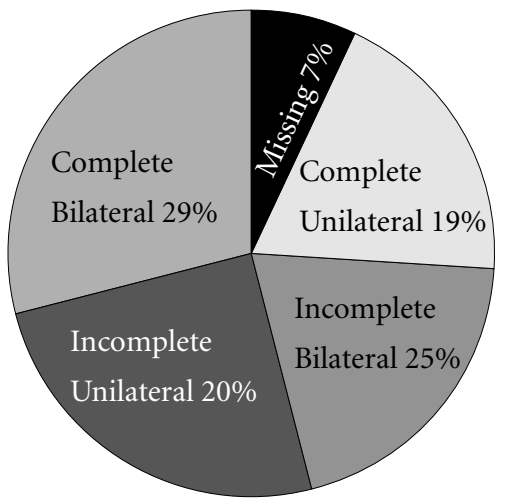

Fig. 1. Type of transitional vertebra

\section{DisCUSSION}

Thirty-percent of our lumbar spine patients had a transitional vertebra. Even when the highest estimates are used, this number is greater than that reported for the general population. This supports our belief that the alteration in mechanics caused by a transitional vertebra may at times contribute to pain generation. Table 2 sums up the findings of other studies reporting the percentages of patients with low back pain who also have a transitional vertebra.

Our percentage of transitional vertebra was exactly equal to the findings of Castellvi and Luoma $(2,4)$. Many of the authors with lower estimations $(7,14)$ used more stringent criteria to count a vertebra as transitional, and other authors did not clearly state all of the inclusion criteria $(6,15)$. This leaves the current estimates of those with a transitional vertebra in the range of $7 \%-30 \%$ in those seeking healthcare for low back pain, either slightly or significantly higher than the $4 \%$ $24 \%$ commonly reported as the number with a transitional vertebra in the general population. This large fluctuation in estimates for the general population amplifies the difficulties in determining the significance of the percentage that we found in our patients. Tini et al (3) found a familial tendency for transitional vertebra and concluded that there may be a genetic factor, which may explain some of the variability in different populations studied.

The high rate of transitional vertebrae in those seeking healthcare for lumbosacral symptoms is noteworthy for interventional spine physicians. For patients receiving epidurals or facet joint injections, it is useful to be aware of a transitional segment prior to initiation of the injection. A transitional segment changes the appearance of the vertebrae, making it difficult to determine the correct lumbar level solely using fluoroscopy. As a transitional segment may not always be visualized on MRI, obtaining plain films whenever possible prior to a lumbar epidural injection will prevent any intra-procedure confusion over level identification.

Likely the most significant aspect of the transitional vertebra is the change in mechanics that its presence causes in the lumbar spine. No study has documented the actual change in biomechanics with a transitional vertebra, but it has been postulated that a bilateral articulation between the transverse processes of the most inferior lumbar vertebra and the sacrum limits the motion of this joint $(5,16)$. This would result in greater forces being imparted to the segment above, and potentially more translation and rotation occurring with movement at this superior level. It has been hypothesized that biomechanical loading conditions are similar between a L5-S1 transitional vertebra and a surgical fusion of this same level, with both placing more stress on the level above (4). The disc at the level above the fused segment has been found to be at increased risk of degeneration (4) Elster's (2) study of 2000 patients reported similar findings in those with a transitional vertebra, with disc bulging or herniation 9 times more likely above the transitional vertebra than at any other level. Castellvi (2) found that only those with Type II transitional vertebra had increased herniations directly above the transition, and that those with a full bony union had a distribution of herniations similar to the normal population. A unilateral articulation may create asymmetrical motion, resulting in increased forces being placed on the articulation itself, or the contralateral facet (17).

Otani et al (5) studied a group of patients to determine if a transitional vertebra contributes to an increased rate of nerve root symptoms from disc herniation and spondylosis. They compared 501 patients with radiculopathy from disc herniation or spondylosis to 508 symptom free controls. There was no difference in incidence of transitional vertebra (13\% for symptomatic group, $11 \%$ controls). However, there was a significantly lower age of onset and an increased rate of herniation ( $17 \%$ vs. $11 \%)$ in those with a transitional vertebra. Otani et al's study also supports the hypothesis that more mechanical stresses are placed on the level above the transitional vertebra, with $83 \%$ of herniations occurring at the level immediately above. Rate of spondylosis was no different between the two groups, but as with herniations, more of the spondy- 
losis was concentrated at the level above in those with a transitional vertebra. This information may be useful for injection purposes when imaging and symptom location leave ambiguity about the level of pain generation.

Luoma et al (4) investigated the relationship between the transitional vertebra, disc degeneration and low back pain in two groups. First they viewed MR images of 2518 - to 20 -year-old men with no history of low back pain. This group of young men had a $24 \%$ rate of transitional vertebra, higher for the general population than reported in other studies. Those men with a transitional vertebra had an increased prevalence of disc degeneration including disc bulging, irregular border of the annulus fibrosus, and a dark nucleus at the level above the transitional vertebra.

Next, Luoma et al (4) viewed MR images of 164 middle-aged men and found a $31 \%$ rate of transitional vertebra. They found equal amounts of degenerative changes in the discs above in those with and without a transitional vertebra. The transitional vertebra also appeared to protect the disc below from degenerating, which has also been confirmed by other authors $(7,14)$. Rates of low back pain in the previous 4 years were equal in these men whether or not they had a transitional vertebra. They concluded that the transitional vertebra accelerated the early development of degenerative changes in the disc above, but by middle age, age related

Table 2. Studies with percentages of transitional vertebra in the low back pain population

\begin{tabular}{|l|c|c|}
\hline Study & $\begin{array}{c}\text { Percent with a } \\
\text { transitional vertebra }\end{array}$ & Number studied \\
\hline Castellvi et al 1984 & $30 \%$ & 200 \\
\hline Elster 1989 & $7 \%$ & 2000 \\
\hline Otani et al 2001 & $13 \%$ & 501 \\
\hline Wigh et al 1981 & $21 \%$ & 200 \\
\hline Tini et al 1977 & $10 \%$ & 4000 \\
\hline Peh et al 1999 & $13 \%$ & 141 \\
\hline Hahn et al 1992 & $12 \%$ & 200 \\
\hline Luoma 2004 & $30 \%$ & 163 \\
\hline O’Driscoll 1996 & $15 \%$ & 100 \\
\hline Chang 2004 & $16 \%$ & 62 \\
\hline
\end{tabular}

changes equalized the degeneration in the two groups.

Thus it appears in symptomatic persons with a transitional vertebra that a frequent pain generator is the motion segment above the transitional segment. Another potential pain source resulting from abnormal mechanics may be the transitional joint itself, particularly in those with a unilateral transitional joint. Connolly et al (18) performed skeletal scintigraphy on 48 patients with low back pain and a transitional vertebra. Eightyone percent of the 48 patients showed increased uptake, or stress-induced change in the bone, at the articulation between the transverse process and the sacrum (unilateral in all but one patient). Those with increased uptake all had a diarthrodial transitional joint, whereas those with a completely fused joint did not show increased uptake.

These findings suggest that a unilateral incomplete articulation frequently results in increased local stress, potentially resulting in pain at this joint. The authors caution that an uptake abnormality alone does not establish the cause of the low back pain, and many young athletes have asymptomatic lower-extremity stress changes. Results of surgical studies support the theory that at times excessive stress at the abnormal joint may be a source of pain. Jonsson et al (19) resected the anomalous transverse joint in $11 \mathrm{pa}-$ tients, with alleviation of pain in 7 of the 11. Santavirta et al (20) reported surgi-

.

\section{.} dence of spondylosis in those with a transitional vertebra.

The most important clinical application gained from the material presented is that given the $30 \%$ rate of transitional segments in our population, we believe that obtaining plain films when considering interventional procedures is very useful. Correlation of the plain films with the patient's MRI will help prevent any confusion from occurring regarding the appropriate level to be treated with diagnostic or therapeutic fluoroscopic spine procedures.

Additionally, for those with a transitional segment, careful attention must be given to determining the accurate pain generator. 


\section{Author Affllation:}

Elva G. Delport, MD

Staff Physician

Christiana Spine Center and

Christiana Care Health Services

4735 Ogletown-Stanton Rd., Ste. 2210

Newark, DE 19713

Tony R. Cucuzzella, MD

Staff Physician

Christiana Spine Center and

Christiana Care Health Services

4735 Ogletown-Stanton Rd., Ste. 2210

Newark, DE 19713
Nancy Kim, MD

Staff Physician

Christiana Spine Center and

Christiana Care Health Services

4735 Ogletown-Stanton Rd., Ste. 2210

Newark, DE 19713

Julie Marley, PT, Dip MDT

Physical Therapist and

Research Coordinator

Christiana Spine Center and

Christiana Care Health Services

4735 Ogletown-Stanton Rd., Ste. 2210

Newark, DE 19713

E-mail: jkmarley@comcast.net
Christine Pruitt, RN, MS

Clinical Director

Christiana Spine Center and

Christiana Care Health Services

4735 Ogletown-Stanton Rd., Ste. 2210

Newark, DE 19713

\section{Anton G. Delport, PT, Dip MDT}

Medical Student

Drexel University College of Medicine

Medical Science Programs

245 North 15th Street, Mail Stop 344

Room 4122, NCB

Philadelphia, PA 19102

\section{REFERENCES}

1. Bertolotti M. Cotributo alla conoscenza dei vizi di differenzazione regionale del rachide con speciale reguardo all assimilazione sacrale della V. lombare. La Radiologia Medica 1917; 4:113-144.

2. Castellvi AE, Goldstein LA, Chan DP. Lumbosacral transitional vertebrae and their relationship with lumbar extradural defects. Spine 1984; 9:493-495.

3. Tini PG, Wieser C, Zinn WM. The transitional vertebra of the lumbosacral spine: Its radiological classification, incidence, prevalence, and clinical significance. Rheum Rehabil 1977; 16:180-185.

4. Luoma K, Vehmas T, Raininko R, Luuk konen R, Riihimaki H. Lumbosacral transitional vertebra: relation to disc degeneration and low back pain. Spine 2004; 29: 200-205.

5. Otani K, Konno S, Kikuchi S. Lumbosacral transitional vertebrae and nerve-root symptoms. J Bone Joint Surg [Br] 2001; 83: 1137-1140.

6. Hahn PY, Strobel JJ, Hahn FJ. Verification of lumbosacral segments of MR images: Identification of transitional vertebrae. $R a$ diology 1992; 182:580-581.

7. Wigh RE, Anthony HF. Transitional lumbosacral discs: probability of herniation. Spine 1981; 6:168-171.
8. Banna M. Clinical Radiology of the Spine and the Spinal Cord. Aspen, Gaithersburg, MD, 1985, pp 61-64.

9. Elster AD. Bertolotti's syndrome revisited. Spine 1989; 14:1373-1377.

10. Nachemson A. Towards a better understanding of low-back pain. Rheumatol Rehabil 1975; 14:129-143.

11. van Tulder, MW, Assendelft WJ, Koes BW, Bouter LM. Spinal radiographic findings and nonspecific low back pain: a systematic review of observational studies. Spine 1997; 22:427-434.

12. Chang HS, Nakagawa H. Altered function of nerve roots in patients with transitional lumbosacral vertebrae. Spine 2004; 29 : 1632-1635.

13. Wies M, Kramer J, Bernsmann K, Ernst Willburger $\mathrm{R}$. The related outcome and complication rate in primary lumbar microscopic disc surgery depending on the the surgeon's experience: comparative studies. Spine J 2004; 4:550-556.

14. O’Driscoll CM, Irwin A, Saifuddin A. Variations in morphology of the lumbosacral junction on sagittal MRI: correlation with pain radiography. Skeletal Radiol 1996; 25:225-230.

15. Peh WC, Siu TH, Jimmy HM. Determining the lumbar vertebral segments on mag- netic resonance imaging. Spine 1999; 24: 1852-1856.

16. McCulloch JA, Waddell G. Variation of the lumbosacral myotomes with bony segemental anomalies. J Bone Joint Surg $[\mathrm{Br}]$ 1980; 62B:475-480.

17. Brault JS, Smith J, Currier BL. Partial lumbosacral transitional vertebra resection for contralateral facetogenic pain. Spine 2001; 26:226-229.

18. Connolly LP, d'Hemecourt PA, ConnolIy SA, Drubach LA, Micheli LJ, Treves ST. Skeletal scintigraphy of young patients with low-back pain and a lumbosacral transitional vertebra. J Nucl Med 2002; 44:909-914.

19. Jonsson B, Stromqvist B, Egund N. Anomalous lumbosacral articulations and low back pain: Evaluation and treatment. Spine 1989; 14:831-834

20. Santavirta S, Tallroth K, Ylinen P, Suoranta $\mathrm{H}$. Surgical treatment of Bertolotti's syndrome. Arch Orthop Trauma Surg 1993; 112:82-87

21. Schers H, Braspenning J, Drijver R, Wensing $M$, Grol R. Low back pain in general practice: Reported management and reasons for not adhering to the guidelines in the Netherlands. Br J Gen Pract 2000; 50: 640-644. 